\title{
Aristotle and Łukasiewicz on Existential Import*
}

\author{
Stephen Read
}

April 5, 2015

\begin{abstract}
Jan Łukasiewicz's treatise on Aristotle's Syllogistic, published in the 1950 s, has been very influential in framing contemporary understanding of Aristotle's logical systems. However, Łukasiewicz's interpretation is based on a number of tendentious claims, not least, the claim that the syllogistic was intended to apply only to non-empty terms. I show that this interpretation is not true to Aristotle's text and that a more coherent and faithful interpretation admits empty terms while maintaining all the relations of the traditional square of opposition.
\end{abstract}

There is a widespread account of Aristotle's logic which claims that it applies only to non-empty terms. We find it recently endorsed in, e.g., the Stanford Encyclopedia article on 'Aristotle's Logic':

"[According to Aristotle] we can get 'Some monsters are chimeras' from the apparently true 'All chimeras are monsters'; but the former is often construed as implying in turn 'There is something which is a monster and a chimera', and thus that there are monsters and there are chimeras. In fact, this simply points up something about Aristotle's system: Aristotle in effect supposes that all terms in syllogisms are non-empty." (Smith, 2009)

According to Church $(1965,420)$, this account stems from Łukasiewicz, who wrote in 1929:

"In Aristotle's logic, empty names may not be the values of ... name variables." (Lukasiewicz, 1963, 103) ${ }^{1}$

* This work was initially supported by Research Grant AH/F018398/1 (Foundations of Logical Consequence) from the Arts and Humanities Research Council, UK.

${ }^{1}$ Italics in the original. He repeated the claim in his definitive work of 1951: "Aristotle does not introduce into his logic singular or empty terms or quantifiers. He applies his logic only to universal terms, like 'man' or 'animal' ... Singular, empty, and also negative terms are excluded as values." (Łukasiewicz, 1957, 130, 72) 
In fact, the claim goes back at least as far as Śleszyński (1921). According to Władisław Bednarowski (1956, 227), "Śleszyński assumes that the terms employed in the Aristotelian logic are not empty," and in Bednarowski (1949, $543,545)$, he noted that Śleszyński's reason was a general belief that the laws of the syllogism and of the square of opposition are otherwise invalidated. ${ }^{2}$

The doctrine was taken up by the Kneales in their influential history:

"In order to justify Aristotle's doctrine as a whole it is necessary, then, to suppose that he assumed application for all general terms with which he dealt," (Kneale and Kneale, 1962, 62)

and by Patzig in his influential study:

"[Aristotle] assumes without further argument that ... in each case [the set of subject (predicate, contrary) terms] have at least one member." (Patzig, 1968, 6-7) ${ }^{3}$

John Martin (2004, 6, 20) and Seuren (2010, 158 ff.) claim in addition that, whereas Aristotle restricted terms in syllogisms to non-empty species terms, it was the medievals who widened the scope of syllogistic to allow empty terms. But against this weight of authority there have been several lone voices: Manley Thompson in 1953, Michael Wedin in 1996, Terry Parsons in his Stanford Encyclopedia article on the Square of Opposition, and Gisela Striker in her recent translation of the Prior Analytics. ${ }^{4}$ They claim that Aristotle himself intended his syllogistic to apply to empty as well as non-empty terms. We need to go back to Aristotle's De Interpretatione (on the nature of syllogistic propositions) and Prior Analytics (on the nature of inference) and look closely at what he actually says there.

In De Interpretatione chs. 7-8, Aristotle distinguishes between four different types of subject-predicate propositions:

\footnotetext{
${ }^{2}$ I owe the reference to Śleszyński to Professor Wojciech Suchoń of the Jagiellonian University in Cracow. Śleszyński's book was reviewed in Łukasiewicz (1923). Śleszyński may have been the first to attribute to Aristotle the exclusion of empty terms from his syllogistic, but he was not the first to query the validity of the Square in the presence of empty terms. See Wu (1969) and Keynes (1884, §§104-6).

${ }^{3}$ We also find it in Corcoran $(1974,104)$ : "Since Aristotle held that every secondary substance must subsume at least one primary substance, $\ldots j$ is an interpretation of $L$ if and only if $j$ is a function which assigns a non-empty set to each member of $U$," and Smiley $(1973,143)$ : "The intended interpretation . . is the familiar one in which the terms are understood as ranging over non-null classes."

${ }^{4}$ Thompson (1953), Wedin (1996), Parsons (2008b), Aristotle (2009, 88).
} 


$\begin{array}{lll} & \text { Affirmative } & \text { Negative } \\ \text { Singular } & \text { Socrates is white } & \text { Socrates is not white } \\ \text { Indeterminate } & \text { Men are white } & \text { Men are not white } \\ \text { Particular } & \text { Some man is white } & \text { Some man is not white } \\ & & \text { Not every man is white } \\ \text { Universal } & \text { Every man is white } & \text { No man is white }\end{array}$

Some have claimed that Aristotle does not include singular propositions among the syllogistic. But this is not true: Aristotle gives several examples of syllogistic reasoning containing singular propositions, e.g.,

Every ambitious man is generous

Pittacus is ambitious

So Pittacus is generous. (Ross, 1928, 70a27) ${ }^{5}$

One argument, much repeated, ${ }^{6}$ is that Aristotle cannot include singular terms in syllogistic propositions because it is essential that terms in them can take both subject and predicate position, and Aristotle explicitly rules out the occurrence of singular terms in predicate position. (See $43 \mathrm{a} 25 \mathrm{ff}$.) But the middle term in the third figure only occurs as subject, so certainly singular terms could always occur in third figure syllogisms, in addition to cases such as the (first-figure) syllogism about Pittacus above. In fact, unless it is circular, ecthesis (that is, the expository syllogism) involves singular propositions essentially. In general, Aristotle treats singular propositions like universal ones. ${ }^{7}$

Indeterminate propositions are ambiguous: contrast 'Men are animals' (interpreted as a universal) with 'Men are running down the street' (usually interpreted as particular). Eukasiewicz $(1957,5)$ claims that Aristotle takes indeterminate propositions to be particular, for Aristotle follows his demonstration of the validity of Darii, which has a particular as minor premise, with the comment (see also 29a28-29):

"The same holds if the premiss $\mathrm{BC}$ should be indeterminate and positive [i.e., affirmative], for the same syllogism will result

\footnotetext{
${ }^{5}$ See also 47b23 ff., where we have the invalid syllogistic form: Aristomenes as an object of thought always exists, Aristomenes is Aristomenes as an object of thought, but it does not follow that Aristomenes always exists; and 47b30, for similarly invalid reasoning, where Aristotle remarks that it is true to predicate 'educated Miccalus' of Miccalus. At II 24, 69a1, war against Thebes is given as an instance of war against neighbours.

${ }^{6}$ See, e.g., Łukasiewicz $(1957, \S 3)$, Bochenski $(1962,13$ C 5, 70) and Kneale and Kneale (1962, 67). Cf. Striker in Aristotle (2009, 76).

${ }^{7}$ See, e.g., 70a16-21, where Aristotle proves that the wise are good by Darapti from the fact that Pittacus was wise and good.
} 
whether we take it to be indeterminate or particular." (26a29-

30)

However, he may equally well mean that whether we take the indeterminate premise to be universal or particular, the syllogistic conclusion will follow, either by Barbara or by Darii. ${ }^{8}$

But on the whole, Aristotle takes syllogistic propositions to be universal or particular, affirmative and negative. The Square of Opposition is an attempt to formalize what Aristotle describes in De Interpretatione $7:^{9}$

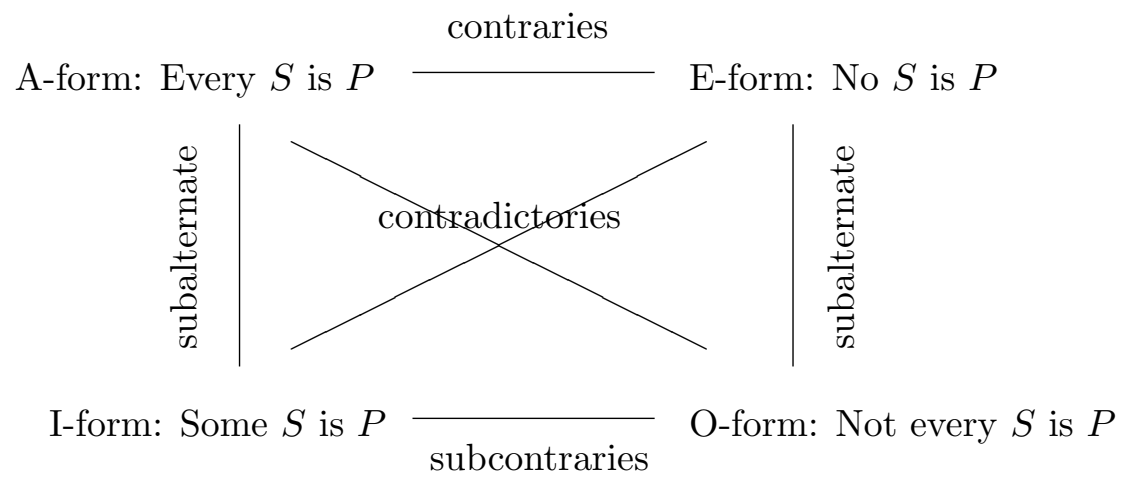

Each universal proposition entails its subalternates. Contraries cannot both be true. Subcontraries cannot be false together. Contradictories cannot both be true and cannot both be false.

Strawson, claiming that Aristotle's logic is restricted to non-empty terms, suggests that each constituent proposition presupposes the non-emptiness of the subject, failing which it has no truth-value:

"If we interpret the propositions of the [square] as neither positively, nor negatively, nor positively and negatively, existential, but as sentences such that the question of whether they are being used to make true or false assertions does not arise except when the existential condition is fulfilled for the subject term, then all the traditional laws hold good together." (Strawson, 1950, 3434 -italics in original)

Geach had expressed a similar view in the previous issue of Mind:

\footnotetext{
${ }^{8}$ I owe this observation to Russell Jones.

${ }^{9}$ In fact, the earliest known reference to the square is in Apuleius of Madaura (2nd century CE). See Londey and Johanson (1987, Appendix 2, 108-12). Apuleius does not mention subalternation in reference to the square.
} 
"If ' $\mathrm{S}$ ' is a pseudo-name like 'dragon' or 'round square', and names nothing, none of the [four Aristotelian] forms has a truthvalue, and so the 'square of opposition' becomes not invalid but inapplicable." (Geach, 1950, 480)

Łukasiewicz $(1957,4)$, as we noted, claims that "in building his logic Aristotle did not take notice either of singular or of empty terms." But Aristotle is happy to speak of the "goat-stag" as an object of knowledge qua not existing (49a24) and to ask if there is a centaur or a God (89b32). Complex terms, which can be empty, e.g., 'sleeping horses' (40a38) are included in the syllogistic. That Aristotle rejects uninstantiated universals does not mean he didn't think there were any empty terms. The Kneales answer their own question, "Are we then to say that Aristotle's teaching is inconsistent ...?" (Kneale and Kneale, 1962, 58-9) by claiming that unless non-empty terms are excluded altogether, there is no consistent interpretation at all which preserves all the relations of the Square.

This despairing conclusion is not warranted. The heart of the issue is the interpretation of O- and A-propositions. For Aristotle, O-propositions do not have existential import, while A-propositions do. Once this is realised, we find a consistent and straightforward reading of Aristotle's view, one which does not restrict the syllogistic to non-empty terms. This reading was recognised by the medieval commentators, and by Moody, Prior and Parsons, among others: ${ }^{10}$

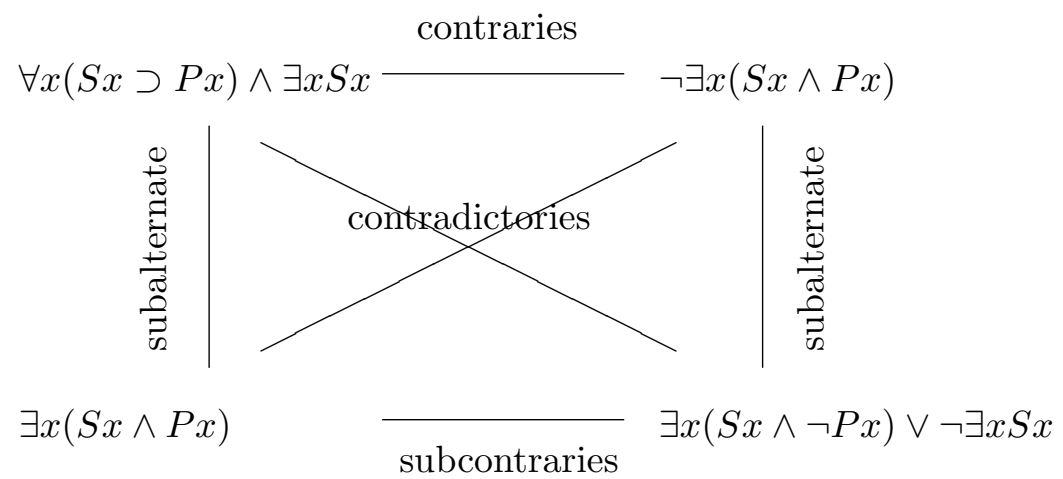

It was not just moderni like Ockham and Buridan who attributed existential import to universal affirmative. In his inteview with Wilfrid Hodges (2011, 182), Niki Pfeifer asks: "Mentioning Aristotle's syllogisms, is Ibn Sina making existential import assumptions? I.e., does 'Every $A$ is a $B$ ' presuppose

\footnotetext{
${ }^{10}$ See, e.g., Burley (2000, 110), Ockham (1974, II 3), Buridan (2001, I 5), Moody (1953, 52), Prior $(1962,169)$ and Parsons (2008a,b).
} 
that $A$ is non-empty?", to which Hodges replies:

"Yes. When there are no $A$ s, he takes affirmative sentences with subject $A$ (for example 'Every $A$ is a $B$ ') as false, and negative statements with subject $A$ (for example 'It's not the case that every $A$ is a $B^{\prime}$ ) as true. I don't think we know where this convention came from, but it's certainly older than Ibn Sina." 11

My claim is that this interpretation goes right back to Aristotle. In fact, Aristotle commonly (though not invariably) expresses the O-proposition as 'Not every $S$ is $P$ ' (or as he usually puts it: ' $P$ does not belong to every $S$ '), and he clearly treats ' $P$ does not belong to every $S$ ' as equivalent to ' $P$ does not belong to some $S$ '. He says of the O-proposition (see also 27b20-21):

"Further, since $[P]$ 's not belonging to some $[S]$ is indeterminateit is true that it does not belong to some both if it belongs to none and if it does not belong to all." (26b15)

By 'indeterminate', he means that there are two possible causes of its truth. Thus ' $P$ does not belong to some $S$ ' (i.e., 'Some $S$ is not $P$ ') is not equivalent to 'Not- $P$ belongs to some $S$ ' (i.e., 'Some $S$ is not- $P$ '). Aristotle rejects obversion: 'Some $S$ is not- $P$ ' is affirmative, and entails the negative proposition 'Some $S$ is not $P$ ', but is not entailed by it. Moreover, 'No $S$ is $P$ ' is the contradictory of 'Some $S$ is $P$ '. 'Some $S$ is $P$ ' entails there is an $S$. So 'No $S$ is $P$ ' does not entail there is an $S .{ }^{12}$ Indeed, Aristotle spends the whole of Prior Analytics I 46 arguing that 'is not $P$ ' and 'is not- $P$ ' are different. He writes:

"It makes a difference in establishing or refuting whether one believes that 'not to be this' and 'to be not-this' signify the same or different things. For example, 'not to be white' and 'to be not-white': ${ }^{13}$ for these do not signify the same, nor is 'to be not-white' the denial of 'to be white'; rather, it is 'not to be white'," (51b6-9)

\footnotetext{
${ }^{11}$ See also Hodges (2012), where an English translation of the relevant passage (AlShifa': Al-Ibara 79.11 to 81.4) is given on pp. 132-3. See also Avicenna (2013). Hodges' answer shows that 'Every $A$ is $B$ ' does not presuppose that there are $A$ s (as in Strawson's interpretation, and as Pfeiffer's question suggests) but entails it.

${ }^{12}$ Else the existence of $S$ would be necessary.

${ }^{13}$ Correcting Striker's translation, where 'not' is omitted from 'not to be white'.
} 
and spends several pages explaining the difference. Consequently, the Oproposition 'Not every $S$ is $P$ ' (or 'Some $S$ is not $P$ ') does not entail that there is an $S .{ }^{14}$

Accordingly, A-propositions, as the contradictories of O-propositions, require the existence of their subject. But the existential import of Apropositions seems to entail that no such propositions concerning corruptible things can be necessary, that is, always true. Ockham (1974, III-2 c. 5, $512)^{15}$ observes that this is contrary to Aristotle's doctrine, when he claims, for example (Prior Analytics I 15, 34b17), that man is an animal of necessity. Does the fact that Aristotle thought that such propositions were demonstrably true show that he did not accord existential import to them? Not at all. Knowledge of such necessities, which ground all scientific knowledge, derives for Aristotle from knowledge of essence presented in intuition, that is, perception. Accordingly, as he says repeatedly in the Posterior Analytics (e.g., 92b5; cf. 93a19): "no one knows the nature of what does not exist." (Ross, 1928) Thus knowledge of essence guarantees existence, and so for Aristotle, unlike Ockham, there is no warrant for scepticism about scientific knowledge. Buridan $(2014,141)$ makes the same point, adding that "Aristotle believed such [propositions as 'A horse is an animal'] to be simply necessary because he thought that the eternity of the world and universal nature could not allow that at some time nothing was a horse or a dog." The important point to realise is that what Ockham means is not that the existential import of affirmatives is contrary to Aristotle's doctrine, but rather the belief that in consequence such propositions cannot be necessary.

Seuren $(2010,125)$ claims that the reading attributing existential import to affirmatives and not to negatives "violates natural intuitions: SOME $F$ is NOT- $G$ clearly implies intuitively that NOT ALL $F$ is $G$,"16 and that "the modern notion of internal negation ... was not available to Aristotle." (Seuren, 2010, 59) This surprising claim seems to overlook Aristotle's careful discussion in Prior Analytics I 46. His account there was the hard-won result of a succession of treatments of negation in the Metaphysics, the Topics, De

\footnotetext{
${ }^{14}$ Nicholas Rescher comments in his translation of Al-Farabi's commentary on the Prior Analytics (Rescher, 1963, 61 fn. 9) (and again at fns. 22a, 31, 41, 44 in the same section) that although he translates the Arabic as 'Some $X$ is not $E$ ': "Literally, that Not every $X$ is $E$. Al-Farabi frequently formulates O-propositions in this way." We can be grateful that he points this out; but he should have translated it more closely to begin with, else we have interpretation rather than translation.

${ }^{15}$ English translation at Ockham $(2007,159)$.

${ }^{16}$ Actually, there is a non-sequitur in Seuren's reasoning here. That 'Some $F$ is not-G' implies there is an $F$ (which is true) does not prevent it entailing propositions (e.g., 'Not all $F$ is $G^{\prime}$ ) which do not.
} 
Interpretatione and Prior Analytics (Bochenski, 1962, §12), distinguishing the various propositions which are in different senses 'opposite' to a given proposition. Thus, e.g., 'No $S$ is $P$ ' is opposite to 'Every $S$ is $P$ ' as its contrary, 'Not every $S$ is $P$ ' is opposite as its contradictory, and 'Some $S$ is $P$ ' is opposite as its subaltern. ${ }^{17}$ These are represented in the Square of Opposition. But Prior Analytics I 46 shows that there is a further opposite, 'Every $S$ is not- $P$ '. Thus among the many contraries of 'Every $S$ is $P$ ' there is both a negative contrary, 'No $S$ is $P$ ', and an affirmative contrary, 'Every $S$ is not- $P^{\prime}$; accordingly, there are two internal negations, one negating the copula and producing the negative contrary, the other negating the predicate and resulting in the affirmative contrary. This affirmative contrary has its own opposites, 'No $S$ is not- $P$ ', 'Not every $S$ is not- $P$ ' and 'Some $S$ is not- $P$ ', as well as 'Every $S$ is $P$ '. Together, they form a cube, with two squares on parallel faces, one for the propositions with positive predicates $(\mathrm{A}, \mathrm{E}, \mathrm{I}, \mathrm{O})$, the other for the negated predicates $\left(\mathrm{A}^{*}, \neg \mathrm{I}^{*}=\mathrm{E}^{*}, \mathrm{I}^{*}, \neg \mathrm{A}^{*}=\right.$ $\mathrm{O}^{*},{ }^{*}$ marking predicate negation) $:{ }^{18}$

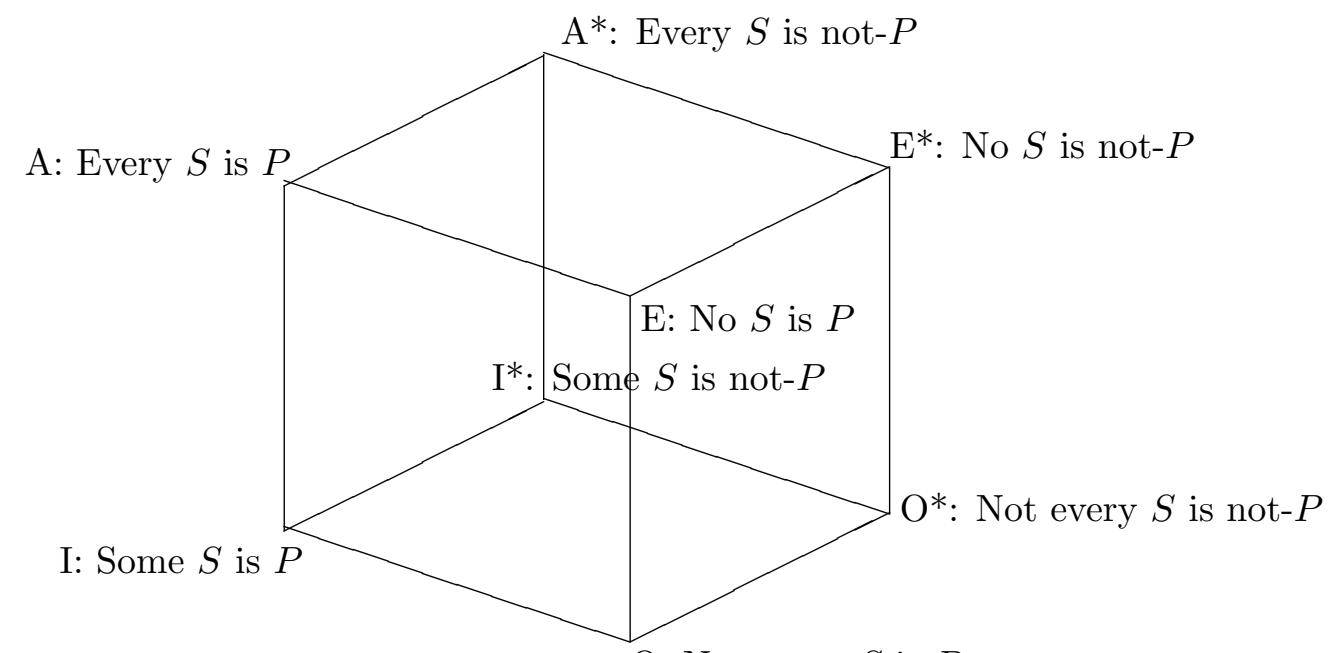

O: Not every $S$ is $P$

The face containing $\mathrm{A}, \mathrm{A}^{*}, \mathrm{I}$ and $\mathrm{I}^{*}$ consists of the affirmatives, that containing $\mathrm{E}, \mathrm{E}^{*}, \mathrm{O}$ and $\mathrm{O}^{*}$ the negatives. The top face $\left(\mathrm{A}, \mathrm{A}^{*}, \mathrm{E}, \mathrm{E}^{*}\right)$ contains the universals, the bottom face $\left(\mathrm{I}, \mathrm{I}^{*}, \mathrm{O}, \mathrm{O}^{*}\right)$ the particular propositions. Each universal node has an affirmative and a negative contrary connected to it, each particular an affirmative and a negative sub-contrary. Moreover, A*

\footnotetext{
${ }^{17}$ See, e.g., Keynes $(1884, \S 53)$.

${ }^{18}$ These eight nodes also appear in Seuren (2010, Fig. 3.7(c), 97), but as the nodes of an octagon. He calls it the "Aristotelian-Abelardian Predicate Calculus".
} 
implies E, A implies $\mathrm{E}^{*}$, I implies $\mathrm{O}^{*}$ and $\mathrm{I}^{*}$ implies $\mathrm{O}$, and each universal node implies the particular node beneath it (as its subaltern).

Seuren's mistake, we now see, is to equate 'Some $S$ is not- $P$ ' with 'Some $S$ is not $P$ '. The former is an affirmative proposition, false if there is no $S$, whereas the latter is a negative proposition, true in those circumstances. Aristotle wrote in Prior Analytics I 46:

"It is clear that 'is not-white' and 'is not white' signify different things and that one is an affirmation, the other a denial." (52a2426)

Nonetheless, Seuren is partly right: Aristotle's system would be "nonvalid" (Seuren, 2010, 14), that is, useless as a logical system, if it applied only to non-empty terms, for there is no logical guarantee that a term is non-empty. Aristotle was too good a logician to miss that. For Aristotle, existence goes with quality, not quantity. The I-proposition 'Some $S$ is $P$ ' is false if there is no $S$ (e.g., goat-stag, centaur, white raven, sleeping horse). So its contradictory, the E-proposition 'No $S$ is $P$ ' is true if there is no $S$. Thus its subaltern, the O-proposition 'Not every $S$ is $P$ ' is also true, whence its contradictory, the A-proposition 'Every $S$ is $P$ ', which Aristotle believes implies the I-proposition, must be false if there is no $S$. Contrast:

'Every 3-year old student is doing a Ph.D.' - arguably false, with 'Every winged horse has wings' - arguably true

Aristotle takes them to be uniformly false if the subject-term is empty. So 'Every $S$ is $S$ ' is false if there is no $S$. Indeed, on Aristotle's principles, 'All chimeras are monsters' is false, as is 'All chimeras are chimeras'. There is only one passage where Aristotle commits himself to the self-predication: " $B$ is affirmed ... of itself" (68a19). However, in this case its truth follows from the given assumption that $A$ belongs to every $B$, so the argument begs the question: unless the A-proposition can be true when $B$ is empty, $B$ is true of itself only on the assumption that $B$ is non-empty. Aristotle does not claim that 'Every $B$ is $B$ ' is always true.

Given that the A-proposition 'Every $S$ is $P$ ' is false if there is no $S$, the corresponding O-proposition must be true either if there is no $S$ or if there is an $S$ which isn't $P$, as we noted Aristotle explicitly says at $26 \mathrm{~b} 15$. The negative proposition 'Not every $S$ is $P$ ' (or 'Some $S$ is not $P$ ') is not equivalent to the "infinite" and affirmative proposition 'Some $S$ is not- $P$ ', as Aristotle emphasises at Prior Analytics I 46, though it is entailed by it.

There is, however, one passage where Aristotle appears to say that selfdenial (that is, 'No $S$ is $S$ ' and 'Some $S$ is not $S$ ') always results in falsehood, 
namely, at Prior Analytics II 15. This is the chapter which Eukasiewicz (1957,9) cites in support of his interpretation, and Thom $(1981,92)$ and others follow him. In this chapter, Aristotle considers whether a syllogism is possible where the premises are opposites - either contraries or contradictories. He observes that the premises are opposites only if one is affirmative and the other negative, and only if the premises share not only the middle term but also the other term, asserting and denying the same thing of the same thing. He then claims that, whereas one can deduce a true conclusion from falsehoods, one cannot deduce a true conclusion from opposites: "for the syllogism always comes about contrary to the facts" (64b9-10: gignetai to pragmati).

However, this does not show that self-denial is always false. For the subject of the conclusion must appear in both premises, including the affirmative premise, so again the argument begs the question. Of course, that premise may be false - at least one of the premises must be, since they are opposites. Nonetheless, both terms are assumed to be non-empty in the affirmative premise. Unless an affirmative proposition about $S$ can be true when there is no $S$, which is exactly the issue before us, the conclusion denying that $S$ is $S$ is false only on the assumption that there is an $S$. That is quite correct on the interpretation proposed here: ' $S$ is not $S$ ' is true if and only if $S$ does not exist.

Finally, what of Aristotle's remark at the end of Prior Analytics I 1 that "we speak of 'being predicated of all' when nothing can be found of the subject of which the other will not be said"? Will this not hold when the subject-term is empty and nothing can be found of the subject at all? Aristotle commits himself in the very next paragraph, at the beginning of chapter 2 to the division of propositions exclusively into affirmative and negative. But some propositions which appear negative are equivalent to others that appear affirmative. Are they affirmative or negative? Just as 'No $S$ is $P$ ' denies what 'Some $S$ is $P$ ' says, so too 'No $S$ is not $P$ ' denies what 'Some $S$ is not $P$ ', that is, 'Not every $S$ is $P$ ', says. So 'No $S$ is not $P$ ' is in fact an affirmation, equivalent to 'Every $S$ is $P$ ', as the dictum de omni says.

I conclude that Lukasiewicz's interpretation is mistaken. The weight of evidence is that Aristotle interpreted affirmative universal propositions the same way he interpreted singular ones, as false when their subject-terms are empty:

"With an affirmation and negation one will always be false and the other true whether [Socrates] exists or not. For take 'Socrates 
is sick' and 'Socrates is not sick': if he exists it is clear that one or the other of them will be true or false, and equally if he does not; for if he does not exist 'he is sick' is false but 'he is not sick' true." (De Interpretatione 13b26-31)

On this interpretation, all the relations which Aristotle accepts are preserved:

- A- and E-propositions are contrary (cannot both be true) and I- and O-propositions are subcontrary (cannot both be false)

- A- and O-propositions are contradictories, as are I- and E-propositions

- A-propositions imply their subaltern I-proposition, and E-propositions their subaltern O-proposition

- I- and E-propositions convert simply ('Some $S$ is $P$ ' implies 'Some $P$ is $S$ ', and 'No $S$ is $P$ ' implies 'No $P$ is $S$ ')

- A-propositions convert accidentally ('Every $S$ is $P$ ' implies 'Some $P$ is $\left.S^{\prime}\right)$ and O-propositions don't convert at all

In conclusion, Aristotle takes syllogistic propositions to be singular, indeterminate, particular or universal. He places no requirement that the terms be non-empty. Eukasiewicz was simply mistaken to claim that he did. Existential commitment goes with quality, not quantity, thus satisfying all the demands of the Square of Opposition. O-propositions can be expressed either as ' $P$ does not belong to every $S$ ' or as ' $P$ does not belong to some $S$ ', and are true if there is no $S$, the corresponding A-proposition then being false.

\section{References}

Aristotle (1963). Categories and On Interpretation. Clarendon Aristotle Series. Clarendon Press, Oxford. Translated with Notes by J.L. Ackrill.

Aristotle (2009). Prior Analytics Book I. Clarendon Aristotle Series. Clarendon Press, Oxford. Translated with an Introduction and Commentary by Gisela Striker.

Avicenna (2013). (Ibn Sina) Al-'Ibara. Philosophia Verlag GmbH, Munich. Translated and Introduced by Allan Bäck. 
Bednarowski, W. (1949). Review of Annales Universitatis Mariae CurieSklodowska, Lublin, Polonia. Section F, vol. i no. 3. Mind, 58:542-45.

Bednarowski, W. (1956). Hamilton's quantification of the predicate. Aristotelian Society Proceedings, 56:217-40.

Bochenski, I. (1962). A History of Formal Logic. Chelsea Pub. Co., New York. Translated and edited by Ivo Thomas.

Buridan, J. (2001). Summulae de Dialectica. Yale U.P., New Haven. G. Klima, Eng. Tr.

Buridan, J. (2014). Tractatus de Consequentiis. Fordham UP, New York. English translation by Stephen Read.

Burley, W. (2000). On the Purity of the Art of Logic. Yale UP, New Haven and London. English translation by P.V. Spade.

Church, A. (1965). The history of the question of existential import of categorical propositions. In Bar-Hillel, Y., editor, Logic, methodology and philosophy of science: Proceedings of the 1964 international congress, pages 417-424. North-Holland, Amsterdam.

Corcoran, J. (1974). Aristotle's natural deduction system. In Corcoran, J., editor, Ancient Logic and its Modern Interpretations, pages 85-131. Reidel, Dordrecht.

Geach, P. (1950). Subject and predicate. Mind, 59:461-482.

Hodges, W. (2011). Interview. The Reasoner, 5:179-83.

Hodges, W. (2012). Affirmative and negative in Ibn Sina. In Dutilh Novaes, C. and Hjortland, O., editors, Insolubles and Consequences, pages 119-34. College Publications, London.

Keynes, J. N. (1884). Studies and Exercises in Formal Logic. Macmillan, London.

Kneale, W. and Kneale, M. (1962). The Development of Logic. Oxford UP, Oxford.

Londey, D. and Johanson, C. (1987). The Logic of Apuleius. Brill, Leiden.

Łukasiewicz, J. (1923). Review of Śleszyński (1921). Ruch Filosoficczny, $8: 107-8$. 
Łukasiewicz, J. (1951). Aristotle's Syllogistic. Clarendon Press, Oxford.

Łukasiewicz, J. (1957). Aristotle's Syllogistic. Clarendon Press, Oxford, 2nd enlarged edition.

Łukasiewicz, J. (1963). Elements of Mathematical Logic. Pergamon Press, Oxford. Translated by Olgierd Wojtasiewicz from the Polish of the second edition, 1958, edited by Jerzy Słupecki. First edition, Warsaw 1929.

Martin, J. N. (2004). Themes in Neoplatonic and Aristotelian Logic. Ashgate, Aldershot.

Moody, E. A. (1953). Truth and Consequence in Mediaeval Logic. NorthHolland, Amsterdam.

Ockham, G. de. (1974). Summa Logicae. Franciscan Institute Publications, St Bonaventure. Edited by P. Boehner et al.

Ockham, G. de. (2007). Demonstration and Scientific Knowledge in William of Ockham. University of Notre Dame, Notre Dame. English translation by John Lee Longeway.

Parsons, T. (2008a). Things that are right with the traditional square of opposition. Logica Universalis, 2:3-11.

Parsons, T. (2008b). The traditional square of opposition. In Zalta, E. N., editor, The Stanford Encyclopedia of Philosophy. Fall 2008 edition.

Patzig, G. (1968). Aristotle's Theory of the Syllogism. Reidel, Dordrecht.

Prior, A. (1962). Formal Logic. Clarendon Press, Oxford.

Rescher, N. (1963). Al-Farabi's Short Commentary on Aristotle's Prior Analytics. University of Pittsburgh Press, Pittsburgh. Translated from the original Arabic with introduction by Nicholas Rescher.

Ross, W., editor (1928). Aristotle's Organon, volume 1 of The Works of Aristotle. Oxford U.P., Oxford. Categories and On Interpretation tr. E.M. Edghill, Prior Analytics tr. A.J. Jenkinson, Posterior Analytics tr. G.R.G. Mure, Topics and Sophistical Refutations tr. W.A. Pickard-Cambridge.

Seuren, P. (2010). The Logic of Language. Oxford UP, Oxford.

Śleszyński, J. (1921). O Logice Tradycyjnej (On Traditional Logic). Wydawnictwo Towaratystwa Filozofucznego w Krakowie, Krakow. 
Smiley, T. (1973). What is a syllogism? Journal of Philosophical Logic, 2:155-80.

Smith, R. (2009). Aristotle's logic. In Zalta, E. N., editor, The Stanford Encyclopedia of Philosophy. Spring 2009 edition.

Strawson, P. (1950). On referring. Mind, 59:320-344.

Thom, P. (1981). The Syllogism. Philosophia Verlag, Munich.

Thompson, M. (1953). On Aristotle's square of opposition. The Philosophical Review, 62:251-265.

Wedin, M. (1996). Negation and quantification in Aristotle. History and Philosophy of Logic, 11:131-150.

Wu, J. S. (1969). The problem of existential import (from George Boole to P.F. Strawson). Notre Dame Journal of Formal Logic, 10:415-24. 